NASA/CR-1999-209686

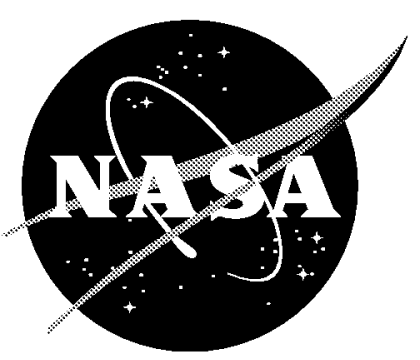

\title{
An Initial Strategy for Commercial Industry Awareness of the International Space Station
}

Catherine A. Jorgensen

F.D.C., Inc./NYMA, Hampton, Virginia 
The NASA STI Program Office ... in Profile

Since its founding, NASA has been dedicated to the advancement of aeronautics and space science. The NASA Scientific and Technical Information (STI) Program Office plays a key part in helping NASA maintain this important role.

The NASA STI Program Office is operated by Langley Research Center, the lead center for NASA's scientific and technical information. The NASA STI Program Office provides access to the NASA STI Database, the largest collection of aeronautical and space science STI in the world. The Program Office is also NASA's institutional mechanism for disseminating the results of its research and development activities. These results are published by NASA in the NASA STI Report Series, which includes the following report types:

- TECHNICAL PUBLICATION. Reports of completed research or a major significant phase of research that present the results of NASA programs and include extensive data or theoretical analysis. Includes compilations of significant scientific and technical data and information deemed to be of continuing reference value. NASA counterpart of peer-reviewed formal professional papers, but having less stringent limitations on manuscript length and extent of graphic presentations.

- TECHNICAL MEMORANDUM. Scientific and technical findings that are preliminary or of specialized interest, e.g., quick release reports, working papers, and bibliographies that contain minimal annotation. Does not contain extensive analysis.

- CONTRACTOR REPORT. Scientific and technical findings by NASA-sponsored contractors and grantees.
- CONFERENCE PUBLICATION. Collected papers from scientific and technical conferences, symposia, seminars, or other meetings sponsored or co-sponsored by NASA.

- SPECIAL PUBLICATION. Scientific, technical, or historical information from NASA programs, projects, and missions, often concerned with subjects having substantial public interest.

- TECHNICAL TRANSLATION. Englishlanguage translations of foreign scientific and technical material pertinent to NASA's mission.

Specialized services that complement the STI Program Office's diverse offerings include creating custom thesauri, building customized databases, organizing and publishing research results ... even providing videos.

For more information about the NASA STI Program Office, see the following:

- Access the NASA STI Program Home Page at http://Www.sti.nasa.gov

- E-mail your question via the Internet to help@sti.nasa.gov

- Fax your question to the NASA STI Help Desk at (301) 621-0134

- $\quad$ Phone the NASA STI Help Desk at (301) 621-0390

- Write to: NASA STI Help Desk NASA Center for AeroSpace Information 7121 Standard Drive Hanover, MD 21076-1320 
NASA/CR-1999-209686

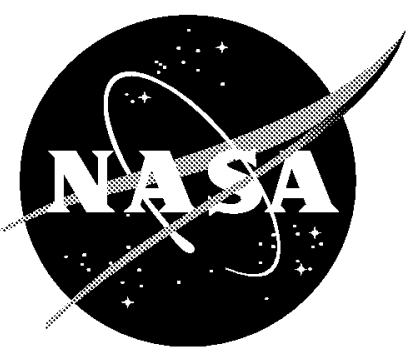

\section{An Initial Strategy for Commercial Industry Awareness of the International Space Station}

Catherine A. Jorgensen

F.D.C., Inc./NYMA, Hampton, Virginia

National Aeronautics and

Space Administration 
Available from:

NASA Center for AeroSpace Information (CASI)

7121 Standard Drive

Hanover, MD 21076-1320

(301) 621-0390

National Technical Information Service (NTIS) 5285 Port Royal Road

Springfield, VA 22161-2171

(703) 605-6000 


\title{
An Initial Strategy for Commercial Industry Awareness of the International Space Station
}

\author{
C. Jorgensen, FDC, Inc., NASA Langley Research Center, 8 Langley Road, M.S. 328, \\ Hampton, Virginia, 23681, USA \\ e-mail: c.jorgensen@larc.nasa.gov
}

\begin{abstract}
The on-orbit assembly of the International Space Station (ISS) began in December 1998. While plans are being developed to utilize the ISS for scientific research, and human and microgravity experiments, it is time to consider the future of the ISS as a worldwide commercial marketplace developed from a government owned, operated and controlled facility. Commercial industry will be able to seize this opportunity to utilize the ISS as a unique manufacturing platform and engineering testbed for advanced technology. Activities to allow the initial planning of the commercialization of the ISS have begun. NASA is currently in the strategic planning phase of the evolution and commercialization of the ISS, an essential and critical step. The Pre-Planned Program Improvement $\left(\mathrm{P}^{3} \mathrm{I}\right)$ Working Group at NASA is assessing the future ISS needs and technology plans to enhance ISS performance. Plans are being formulated for ISS enhancements to accommodate commercial applications and the Human Exploration and Development of Space mission support. As this information develops, it is essential to disseminate this information to commercial industry, targeting not only the private and public space sector but also the non-aerospace commercial industries. An approach is presented for early dissemination of this information that includes ISS baseline system information, baseline utilization and operations plans, advanced technologies, future utilization opportunities, ISS evolution and Design Reference Missions (DRM). This information is being consolidated into the ISS Evolution Data Book, an initial source and tool to be used as catalyst in the commercial world for the generation of ideas and options to enhance the current capabilities of the ISS.
\end{abstract}

\section{Introduction}

The assembly of the International Space Station (ISS) is underway and within a relatively short period of time, by 2004, will be completed and fully operational. The NASA Administrator, Mr. Daniel S. Goldin, declared that $30 \%$ of the U.S. Laboratory space would be commercialized as part of the directive of the Commercial Space Act of 1998 [Reference 1]. Recently, Mr. Goldin stated that "nothing would please me more than if commercial demand for Station accommodations reached 40, 50 or even 80 percent" [Reference 2]. Any amount of commercial use of the ISS could distribute the resource burden of continual ISS operations between NASA and the commercial sector, which would be a 
International Space Station - The Next Space Marketplace

plus for both sides. This vision of commercial use of the ISS up to $80 \%$ is a signal for all sides involved to act now in planning for commercial ventures on the ISS.

Commercialization is a "...private sector, profit-seeking entity using its own or borrowed and/or invested funds to carry out activities intended sooner or later to result in products or services that can be sold at a profit through a market, either to government or non-government customers or to a mixture of the two" [Reference 3]. The current NASA thinking is that industry will utilize the ISS for commercial research to develop new technologies that can be used in terrestrial-based commodities. This can be taken a step further to use the ISS as a possible and probable production facility and as a facility in which products and services can be bought and sold (i.e. products, entertainment,), hence, a space marketplace.

NASA has developed a plan for commercializing the ISS, however, there is a need for supplemental activities to occur now in addition to those included in NASA's plan. Acting now can ensure the timely and effective development of the ISS as a viable and acceptable marketplace by commercial industry.

\section{Parallel Perspectives}

\subsection{Existing Strategy}

The current NASA strategy for commercializing the ISS is outlined in the Commercial Development Plan for the International Space Station [Reference 4]. The tactics included in this strategy include: 1) an independent market assessment, 2) identification of barriers to market entry, and 3) the establishment of a non-government organization (NGO) for ISS utilization development. The time frame for the completion of the first two activities would be June 1999 and the end of 1999 for the establishment of an NGO. This strategy is well thought out with necessary steps for creating a new marketplace, however, the focus here is primarily from the NASA perspective. The studies and analyses outlined in the plan are directed towards the NASA implementing commercialization of the ISS.

\subsection{A Commercial Industry Perspective}

Developing the ISS into a marketplace should also be addressed from the commercial industry perspective. The initial transition of this facility to a

commercial marketplace could place a heavy financial burden on commercial firms. It is evident that in the U.S., at least, the government must develop cost 
International Space Station - The Next Space Marketplace

cutting processes for ISS access to entice the commercial firms to utilize the facility. The government may initially have to subsidize some of the expenditures of commercial companies who desire to venture into this new marketplace. This transition phase will allow NASA, in conjunction with commercial industry, to increase the efficiency of ISS operations processes and thus reduce operating costs. These cost reductions will provide the commercial firms with higher returns on investments (ROI) and ultimately entice more commercial firms to enter the ISS space marketplace. In addition to the investment burden which commercial companies will face, the acquisition of programmatic and technical information pertaining to the feasibility of proposed ISS-based commercial ventures presents additional roadblocks.

Commercial industry must be made aware of the opportunities that are available on the ISS. This should happen now so that commercial industry can initiate their planning strategies as NASA has done. It is going to take time for commercial industry to accept the ISS as a viable marketplace. Industry executives and analysts will need to look at cost versus ROI. Industry will also need facility and utilization information to determine from an operational standpoint whether they can use the ISS as a marketplace. This information must be disseminated to industry quickly and thoroughly in order for informed decisions to be made. Currently, there are Commercial Space Centers (CSC), usually universities, working in conjunction with NASA as an avenue for industrial firms to approach the space program. When an industrial interest becomes convinced that a space research activity has a potential economic benefit, it can approach a CSC with a proposal [Reference 5]. From these initial discussions, the CSC will determine whether the space research activity is feasible and will work with them to integrate the research into the ISS Program.

The CSCs work with approximately 135 industrial firms at this time. This avenue has been an effective means for commercial industry to take to get to space. However, this has been primarily for research purposes only and many of the companies associated with the CSCs are already involved in the space industry in some manner. There are many firms who are not affiliated with any space related-industry who may be interested in utilizing the ISS as a marketplace in areas other than research. Additionally, there are many firms who have not even considered the possibility of utilizing the ISS in any manner for the mere fact that they are unaware that it is possible, or will be possible in the relatively near future. It is this part of commercial industry that this strategy targets, as is explained in the next section. 
International Space Station - The Next Space Marketplace

\subsection{Commercial Industry Awareness}

Many firms within the U.S. and worldwide are unaware of the fact that they could someday utilize the ISS for new product development in such areas as telecommunications, pharmaceuticals and materials processing, as a production facility, or even as a service provider, as in the entertainment industry. Even if they are aware of this fact, their planning on ways to utilize the ISS platform should begin now. For any industry to begin planning, they must have some initial source of information to help them determine potential venture characteristics such as cost, operations, facilities, resources, legal, potential for expansion, etc. There is currently an overwhelming amount of information on the ISS that includes the planning and process documentation, technical specifications, assembly information and the list goes on. Not only is the amount of information mountainous, it is also mostly unavailable to the general public at this time. While this is understandable from the perspective of NASA and its contractors, from an industry perspective the unavailability of this information can be construed as another obstruction in their journey towards acceptance and utilization of the ISS. A commercial firm interested in obtaining information to establish the initial viability of a commercialization concept could find it to be an almost impossible task. Where would they begin? They would first have to determine what information they needed and request it from the owning entity, if they knew who that was. Even if they did get a positive response from the information owner, they would then have to sift through an enormous amount to extract the information they need for their application.

Currently, an informational reference source is being developed at NASA Langley Research Center in Hampton, Virginia, sponsored by the Director of Advance Projects, Office of Space Flight at NASA Headquarters in Washington, D.C. as an initial solution to this potential roadblock. The document entitled "The International Space Station Evolution Data Book" [Reference 6] provides a focused look at the opportunities and drivers for the enhancement and evolution of the ISS during its assembly and beyond the assembly complete stage. These enhancements would expand and improve the current baseline capabilities of the ISS and help to facilitate the conversion of the ISS into a marketplace by and for the public sector.

The purpose of the data book is threefold. First, it provides a broad, integrated systems view of the current baseline design of the ISS systems and identifies potential growth and limitations of these systems. Second, it presents current and future options for the application of advanced technologies to these systems and discusses the impacts these enhancements may have on interrelated systems. Finally, it provides this information in a consolidated 
International Space Station - The Next Space Marketplace

format to scientific and commercial entities to help generate ideas and options for creating new technologies and products, and to assist in determining potential beneficial uses of the ISS in commercial business.

\section{ISS Evolution Data Book Description}

The ISS Evolution Data Book is composed of six sections, the first of which is the introduction. The second, third and fourth sections give a broad, integrated systems view of the ISS baseline design. Section 2 of the data book provides a brief overview of each of the 22 major components of the ISS. This includes individual laboratories owned by the ISS International Partners, the integrated truss segments, the various nodes, propulsion modules, and science facility modules. These brief descriptions provide the readers with information on the overall station.

Section 3 covers nine of the individual critical sub-systems onboard the ISS. These include Power; Thermal; Communications; Command and Data Handling; Guidance, Navigation and Control; Propulsion; Environmental Control and Life Support Systems; Robotics; and Structures and Mechanisms. The document provides high-level technical overviews of each system, the capabilities of each, the potential limitations of each, and a description of potential growth opportunities and limitations.

Section 4 provides information on the current baseline plans for the operation and utilization of the ISS. This section includes plans for utilization of crew time, traffic models, space availability, and resource availability including bandwidth and data rates for communications, power, thermal, and system ground commanding availability. It also includes descriptions of each of the internal facilities on board the ISS, which will provide specific services to payloads that are either currently planned, research-based activities or future commercial-type endeavors. These include facilities such as the Combustion Facility and Fluid Physics Facility that are used in materials research, the Life and Microgravity Science Gloveboxes which are fully contained facilities for performing biological or materials activities, and many more. Along the same lines, it provides location and resource information on the external payload facilities including the U.S. and Japanese facilities. The European Space Agency facility and Russian facility will be described as information becomes available.

This baseline information will assist commercial industry in developing their view of the ISS as a potential marketplace. Industries can utilize this information to determine if their specific technologies can benefit the ISS and/or if the ISS offers an environment, which they could utilize in a commercially viable manner. 
The next two sections of the data book present current and future options for the application of advanced technologies. Section 5 presents the advanced technologies that are being investigated by the Pre-Planned Program Improvement $\left(\mathrm{P}^{3} \mathrm{I}\right)$ Working Group, led by the NASA Johnson Space Center in Houston, Texas. These advanced technologies will provide enhanced capabilities to the ISS that may be beneficial to commercial industry. The section discusses proposed ISS technology enhancements that are known at this time and provides roadmaps for the investigation of each area. This information may entice commercial firms to look at their own technologies for enhancement of ISS systems.

Finally, Section 6 summarizes current Design Reference Missions (DRM) that are being investigated for post-assembly complete utilization and enhancements. These include free-flying satellite servicing, enhanced communications capabilities utilizing the Advanced Communications Tower and utilizing a new module, TransHab, for increased pressurized volume onboard the ISS (See Fig. 1). Each of these DRMs and the others that are presented in this document provide options for ISS enhancements that could be achieved via commercialization.

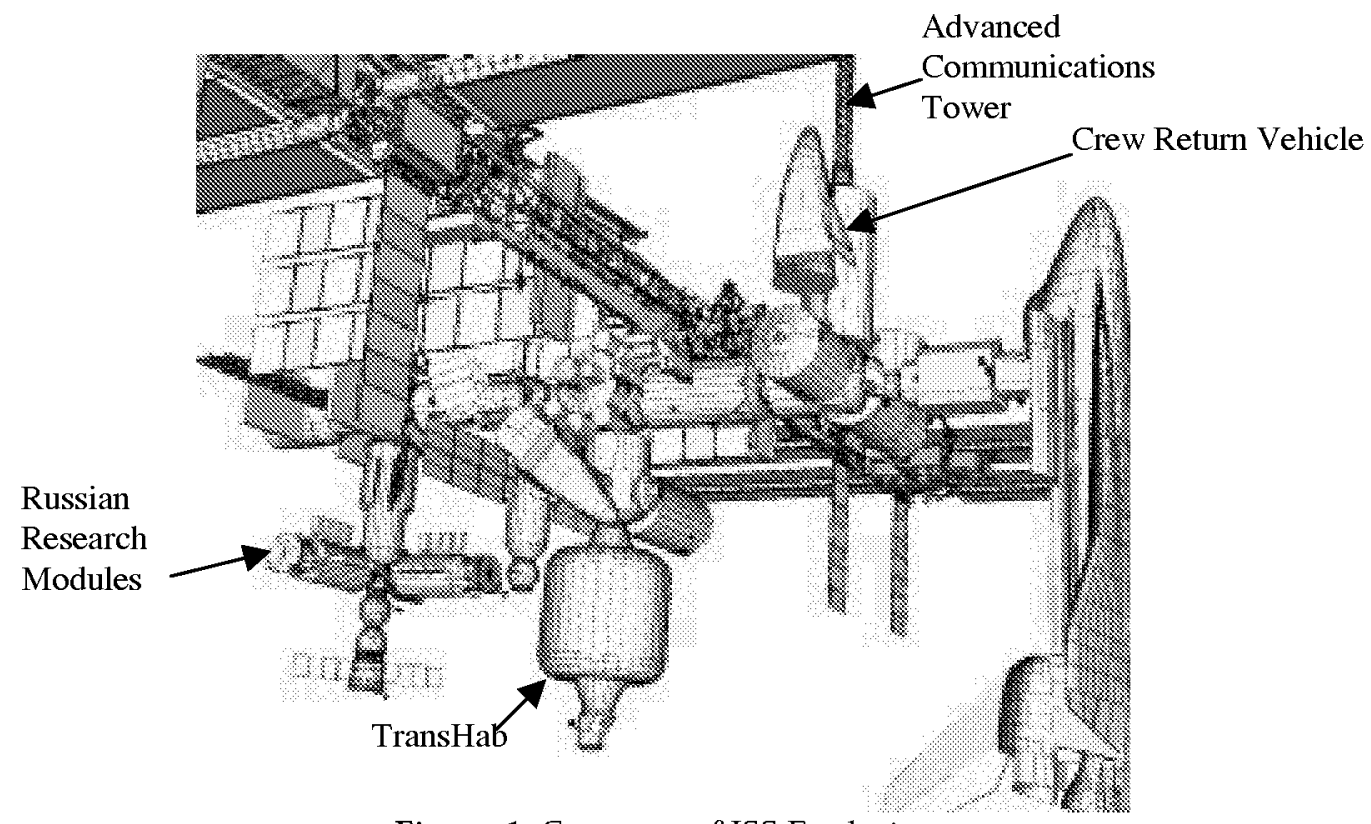

Figure 1. Concepts of ISS Evolution 
International Space Station - The Next Space Marketplace

\section{Effective Utilization of the Data Book}

The ISS Evolution Data Book is intended to provide high level technical information to the science community, commercial industry, academia, and the general public. Used as a desktop reference, the data book not only provides high-level finger-tip information on the technical aspects of the ISS, but also provides further references for more detailed information.

This data book should be used as a planning tool and a desk reference and not as a design tool for the development of a system, product, or any other entity. It is to be used for reference only to provide a high-level technical overview of the ISS, its capabilities, future options for enhancements, and opportunities for commercial use. It is hoped that the data book can act as a catalyst to facilitate innovative uses of the ISS for commercial ventures and to facilitate the application of non-aerospace technologies to enhance the many capabilities of the ISS.

\section{Marketplace Outreach}

The data book will be used as part of the marketing strategy for developing the ISS as an international marketplace. NASA Langley Research Center, in conjunction with NASA Headquarters, plans to distribute this information through the CSCs, through face-to-face contact at commercial and industrial trade shows, through the NASA commercialization initiatives at headquarters, Johnson Space Center, and Langley Research Center, and via a publicly available web site. This web site is planned to have links not only to NASA public web sites, but also to business associations. As information becomes available, the document will be revised to remain current for industry. The updated information will be available electronically and via hard copy if desired. A database of interested firms will be established to ensure that the flow of information remains constant.

\section{Summary}

The commercialization of the ISS can be facilitated by informing industry of its potential and limitations. It is important that this information be disseminated now to as much of commercial industry as possible, both in the U.S. and globally. For the ISS to become a global marketplace, ISS-specific information must be communicated to guide the initiative and ambitions of public sector industry towards space. The use of the ISS Evolution Data Book to stimulate the creative expertise of industry is just one step towards commercializing the ISS. As the developing information is disseminated throughout industry, the acceptance and - hopefully - adoption of the ISS as 
a global marketplace will become a reality. However, this must be done now. We cannot wait until the ISS is fully complete and then hope that industry will fall in line. Providing the information to as widespread an audience as possible will help the commercial community to begin to look at the ISS as a marketplace now, and allow them to develop potential commercial uses for the ISS.

\section{Acknowledgements}

This work was supported by the NASA Langley Research Center in Hampton, Virginia, under contract NAS1-96013, with Mr. Jeff Antol as technical monitor. I would also like to acknowledge the Spacecraft and Sensors Branch at NASA Langley Research Center.

\section{References}

1. Public Law 105-303: Commercial Space Act of 1998, Section 101 from the $105^{\text {th }}$ Congress, October 28, 1998

2. Goldin, Daniel S.: , The National Importance of the Development of Space, Speech presented to the U.S. Chamber of Commerce at the Forum on the Future Development of Space, March 16, 1999

3. Logsdon, J.M.: Commercializing the International Space Station: current US thinking, Space Policy, Vol. 14, pp. 239-246, November 1998

4. NASA: Commercial Development Plan for the International Space Station, November 16, 1998

5. NASA: The International Space Station: Improving Life on Earth and in Space The NASA Research Plan: An Overview. NP-1998-02-232-HQ, Rev 1, p. 41. http://www.hq.nasa.gov/office/olmsa/ISS/cover.htm

6. Jorgensen, C., Antol, J., F. Stillwagen, C. Roithmayr, P. Cosgrove, G. Hajos, J. Hall, Jr., G. Ganoe, "International Space Station Evolution Data Book", NASA/SP-19996109, NASA Langley Research Center, November 1999. 


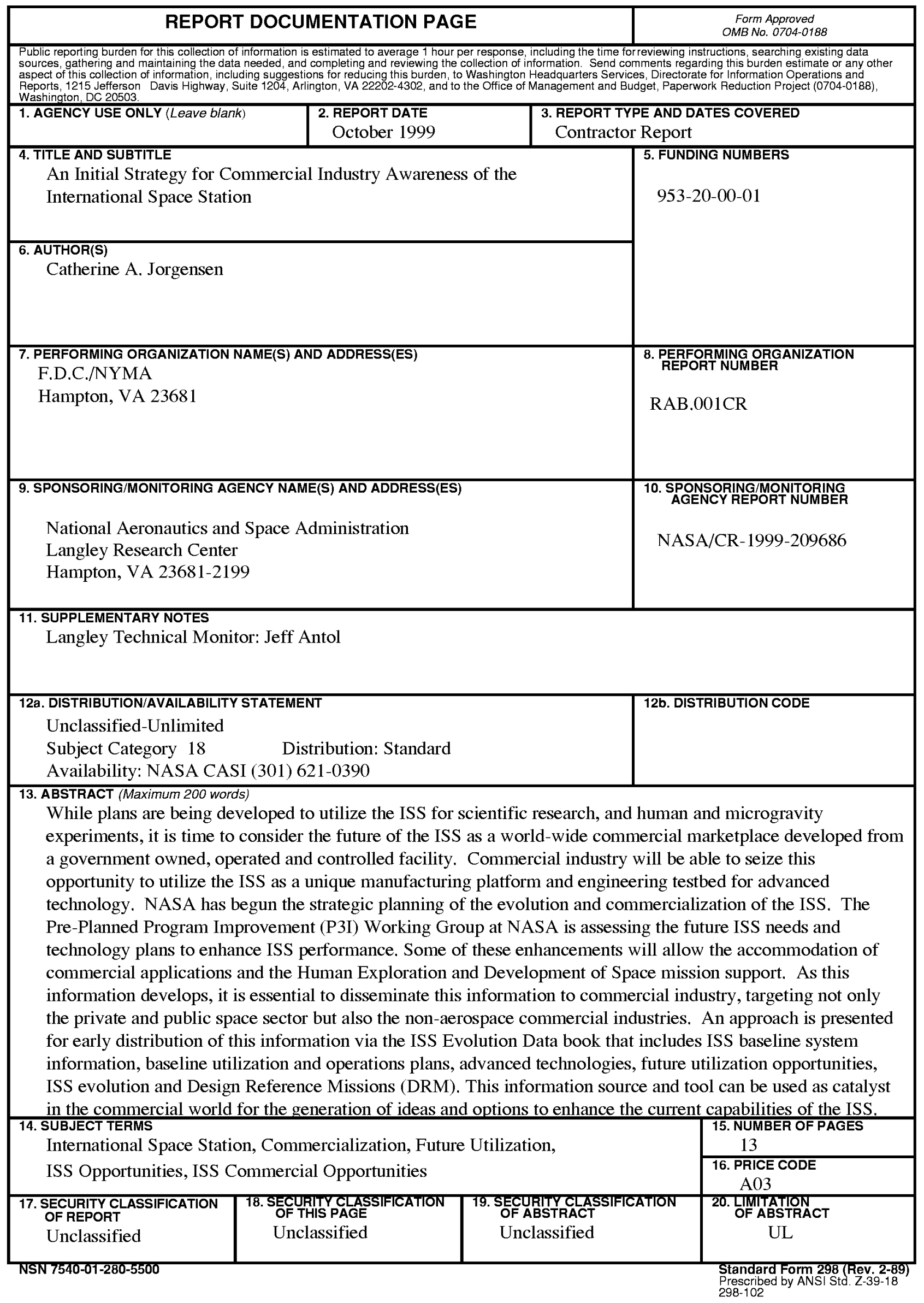

